\title{
Kistik fibrozis transmembran regülatör (CFTR) genindeki M470V polimorfizmi ve erkek infertilitesi
}

\section{M470V polymorphism in the cystic fibrosis transmembrane conductance regulator (CFTR) gene and male infertility}

\author{
Ahmet Gökçe', Deniz Gül
}

\section{öz}

AMAC,: Erkek infertilitesine neden olan durumlardan biri de kistik fibrozistir (KF). KF erkeklerde infertiliteye, genellikle konjenital bilateral vas deferens agenezisine (KBVDA) yol açarak neden olmaktadır. Bununla birlikte, KF genindeki mutasyonlar ve polimorfizmlerin spermatogenezi nasıl etkilediği ile ilgili çalışmalar sınırlıdır. Bu çalışma, KBVDA olmayan erkeklerde şiddetli oligozoospermi veya nonobstrüktif azoosperminin (NOA) KF genindeki M470V polimorfizmi ile birlikteliğini araştırmayı amaçlamıştır.

GEREÇ ve YÖNTEM: Çalışmaya, hastanemiz androloji polikliniğine infertilite nedeniyle başvuran, semen analizinde şiddetli oligozoospermi veya NOA saptanan 33 hasta dahil edildi. Hastalardan, kistik fibrozis transmembran regülatör (CFTR) gen analizi istendi ve yapılan analizde, M470V polimorfizminin olup olmadığı değerlendirildi.

BULGULAR: Hastaların yaş ortalaması 34,3 idi. Otuz üç hastanın 13 'ünde $(\% 39,4)$ NOA, 20 'sinde ise $(\% 60,4)$ şiddetli oligozoospermi mevcuttu. Sekizi (\%62) NOA grubunda ve 11'i (\%55) şiddetli oligozoospermi grubunda olmak üzere, toplam 19 (\%58) hastada M470V polimorfizmi mevcuttu. Daha önce sağlıklı gönüllülerle yapılmış çalışmalarda bildirilen oranlarla (\%28-47) karşılaştırıldığında, hasta grubumuzdaki M470V polimorfizmi sıklığı, toplumdaki beklenen orana göre yüksek bulundu.

SONUÇ: Bu çalışmanın sonuçları, şiddetli oligozoospermi veya NOA'sı olan kişilerde gözlenen artmış M470V polimorfizminin, KBVDA dışında spermatogenez üzerine de etkileri olabileceğini düşündürmektedir. Ancak, bu konuyla ilgili daha kapsamlı çalışmalara ihtiyaç vardır.

Anahtar Kelimeler: Azoospermi, CFTR, infertilite, M470V polimorfizmi, oligospermi

\section{Giriș}

Erkek infertilitesi; korunmasız cinsel ilişkiye rağmen bir y1lın sonunda konsepsiyon meydana gelmemesi veya çocuk sahibi olunamaması olarak tanımlanmaktadır. ${ }^{[1]}$ Evli çiftlerin yaklaşık \%10-15'i bebek sahibi olabilmek için tıbbi yardım

'Sakarya Üniversitesi Tıp Fakültesi, Üroloji Anabilim Dalı, Sakarya

Yazışma Adresi / Correspondence:

Doç. Dr. Ahmet Gökçe

Sakarya Üniversitesi Tıp Fakültesi Üroloji Anabilim Dalı, Sakarya, Türkiye

Tel. $\quad+902648884051$

E-mail: gokce@sakarya.edu.tr

Gelis / Received: $\quad$ 08.09.2017

Kabul / Accepted: 12.09.2017

\section{ABSTRACT}

OBJECTIVE: Cystic fibrosis (CF) is one of the conditions that cause male infertility. CF is caused infertility in men by usually resulting congenital bilateral vas deferens agenesis (CBVDA). However, studies on how mutations and polymorphisms in CF gene affect spermatogenesis are limited. In this study, we aimed to investigate the association of severe oligozoospermia or nonobstructive azoospermia (NOA) with M470V polymorphism in the CF gene in non-CBVDA males.

MATERIAL and METHODS: Thirty-three patients with severe oligozoospermia or NAO who were admitted to our andrology clinic because of infertility were enrolled in the study. Cystic Fibrosis Transmembrane Conductance Regulator (CFTR) gene analysis was performed to evaluate the presence of $\mathrm{M} 470 \mathrm{~V}$ polymorphism.

RESULTS: The mean age was 34.3 years. 13 of 33 patients $(39.4 \%)$ had $\mathrm{NOA}$, and $20(60.4 \%)$ had severe oligozoospermia. M470V polymorphism was present in $19(58 \%)$ patients, 8 of them were in the NOA group $(62 \%)$ and $11(55 \%)$ were in the oligozoospermia group. The frequency of $\mathrm{M} 470 \mathrm{~V}$ polymorphism in our patient group was found higher than expected in the population when compared with the rates reported in previous studies (28-47\%) with healthy population.

CONCLUSION: The results of this study suggest that increased M470V polymorphism in individuals with severe oligozoospermia or NOA may also have effects on spermatogenesis other than CBVDA. However, there is a need for more extensive studies on this topic.

Keywords: Azoospermia, CFTR, infertility, M470V polymorphism, oligospermia

talep etmektedir. ${ }^{[2]}$ Bu çiftlerin de yaklaşık \%50'sinde erkek üreme sistemi disfonksiyonuna rastlanmaktadır. ${ }^{[3]}$ Erkek infertilitesinin \%40'ında neden tam olarak bilinmemekle birlikte, genetik faktörler bu nedenler arasında önemli bir yer tutmaktadır. ${ }^{[4]}$ Kistik fibrozis (KF) de erkeklerde infertiliteye neden olabilen genetik hastalıklardan biridir. KF; kronik akciğer hastalığı, pankreas yetmezliği, intestinal obstrüksiyon, erkeklerde infertilite ve terde klor miktarında artış ile karakterize olan kalıtsal bir hastalıktır. Hastalık, kistik fibrozis transmembran regülatör (CFTR) genindeki mutasyonlara bağlı olarak gelişmektedir. Hastalıktan sorumlu olan gen 1989 yılında klonlanmıştır. 7q31 bölgesine haritalanan gen $250 \mathrm{~kb}$ uzunluğunda olup, iyon kanalı 
olarak fonksiyon gösteren bir membran proteinini kodlamaktadır. ${ }^{[5,6]} \mathrm{Bu}$ gendeki mutasyonlar sonucunda CFTR proteini hatalı sentezlenerek, klor iyonlarının epitelyum hücrelerinden yanlış taşınmasına ve bunun sonucunda da vücut sıvilarının viskozitelerinin artmasına ve salgı bezlerinin kanallarında tıkanıklıklara neden olur. KF hastalarının \%95'inden fazlasında obstrüktif azoospermiye neden olan konjenital bilateral vas deferens agenezisi (KBVDA) bulunur. ${ }^{[7-10]}$ KBVDA dışında, non-obstrüktif azoospermi (NOA), CFTR genindeki mutasyonlar ile bağlantılı olabilecek diğer bir erkek infertilitesi nedenidir. ${ }^{[11-13]}$ CFTR geninde, KF'nin çeşitli klinik fenotiplerine katkıda bulunan 2000'den fazla mutasyon ve polimorfizm saptanmıştır. ${ }^{[14]}$ KBVDA hastalarında, CFTR geninin en yaygin mutasyonu T5 varyant1, bunu takiben F508 del ve R117H mutasyonları olur. ${ }^{[15]}$ Yapılmış bazı çalışmalar, ekson 10 'daki M470V nokta mutasyonunun (470 kodonunda metioninden valine değişme), KBVDA ile ilişkili bir başka faktör olabileceğini göstermiştir. ${ }^{[16,17]}$ Bununla birlikte; NOA ve CFTR mutasyonları arasındaki bağlantı açık değildir ve literatürde NOA veya şiddetli oligozoospermi için M470V gen tarama verileri sınırlıdır. Bu çalışma, infertil erkeklerde şiddetli oligozoospermi veya NOA'nın KF genindeki M470V polimorfizmi ile birlikteliğini araştırmayı amaçlamıştır.

\section{GEREÇ ve YÖNTEM}

Hastanemiz androloji polikliniğine 01.01.201501.07.2016 tarihleri arasında başvuran hastalardan, yapilan fizik muayene ve laboratuvar değerlendirmeleri sonucunda, semen analizinde şiddetli oligozoospermi $(\mathrm{ml}$ başına $<5$ milyon sperm hücresi) veya NOA saptanan ve bunların dışında ek patolojisi olmayan 33 hasta çalışmaya dahil edildi. Hastalardan CFTR gen analizi istendi. Yap1lan gen analizinde M470V polimorfizminin olup olmadığ değerlendirildi. Elde edilen oranlar, daha önce sağlıklı bireylerle yapılmış çalışmalardaki oranlarla karşılaştırıldı.

\section{BULGULAR}

Çalışmaya dahil edilen hastaların yaş ortalaması 34,3 (24$55)$ idi. Otuz üç hastanın 13 'ünde $(\% 39,4)$ NOA, 20 'sinde $(\% 60,6)$ ise şiddetli oligozoospermi mevcuttu. Toplamda 19 (\%58) hastada M470V polimorfizmi saptandı. Grupları ayrı ayrı değerlendirdiğimizde, NOA grubunda 8 (\%62) hastada, şiddetli oligozoospermi grubunda ise 11 (\%55) hastada M470V polimorfizmi mevcuttu. Daha önce sağlıklı gönüllülerle yapılmış çalışmalarda bildirilen oranlarla (\%28-\%47) karşılaştırıldığında, hasta grubumuzdaki M470V polimorfizmi sıklığı toplumdaki beklenen orana göre yüksek bulundu.

\section{TARTIȘMA}

Erkek infertilitesi, geniş etiyolojik heterojeniteye sahiptir ve çoğu vakada güçlü bir genetik bileşenden şüphelenilmektedir. Anamnez ve fizik muayenesinde infertilite nedenini göstermeyen ciddi oligozoospermik veya azoospermik hastaların, monogenik bir hastalık nedeniyle etkilendiğinden şüphelenilmektedir. ${ }^{[18]}$ Altta yatan genetik anomaliyi saptamak, spermatojenik başarısızlığın nedenini aydınlatmak, çift için yeterli genetik danışmanlık sağlamak ve kullanılacak en iyi yardımcı üreme teknolojisi yaklaşımına karar vermek için gereklidir. Azoospermisi olan erkeklerde bulunan en yaygın genetik anomaliler, Klinefelter sendromu (KS; 47, XXY) ve Azoospermi Faktörü (AZF) bölgelerinde $\mathrm{Y}$ kromozomunda tekrarlayan mikrodelesyonlardır ve bunlar 0,1-5 milyon/ml sperm konsantrasyonuna sahip erkeklerde sırasıyla $\% 8$ ve $\% 5$ 'ini açıklamaktadır. Bu katkıların, spermatojenik başarısızlığın daha şiddetli biçimlerinde sırasıyla $\% 15$ ve $\% 10$ 'a yükseldikleri ve NOA oluşturduğu bildirilmiştir. ${ }^{[19]}$ Yakın tarihli çok sayıda araştırma, kromozom anormalliğinin, Y kromozomu delesyonunun ve ilgili gen mutasyonunun spermatogenezin bozulması ile ilişkili olduğunu göstermiştir. Kosova ve ark., 250.000 tekli nükleotid polimorfizm (SNP) alanını analiz ederek, erkek infertilitesiyle yakından ilgili olan 9 SNP alanının olduğunu göstermişlerdir. ${ }^{[20]}$ Gen seviyesinde erkek infertilitesi, protamin gen mutasyonları ${ }^{[21,22]}$, 5-alfa redüktaz eksikli$\breve{g}^{\left[{ }^{[23]}\right.}$, androjen reseptörü gen mutasyonlar1 ${ }^{[24,25]}$ ve CFTR gen mutasyonlarıyla bağlantılıdır. ${ }^{[12,26-33]}$ Çalışmamızda, CFTR genindeki M470V polimorfizminin NAO ve şiddetli oligospermisi olan erkeklerde sıklığı irdelenmiş olup, toplumumuzdaki sağlıklı popülasyonda M470V sıklığı ile ilgili veri bulunmamaktadır. Literatürde yapılmış çalışmalara bakıldığında; Nefzi ve ark.'nın yaptı̆̆ı, kistik fibrozis ile M470V polimorfizminin ilişkisinin araştırıldığı çalışmada, Tunus toplumunda sağlıklı popülasyonda M470V polimorfizmi \%40 olarak bulunmuştur. ${ }^{[34]}$ Stankovic ve ark.'nın kronik obstrüktif akciğer hastalığı ile M470V polimorfizminin birlikteliğini araştırdıkları çalışmada, Sırp toplumunda sağlıklı popülasyondaki M470V sıklığı $\% 47,1$ olarak saptanmıştır. ${ }^{[35]}$ Huang ve ark.'nın sağlıklı Çin popülasyonunda yaptıkları analizde ise M470V sıklı̆̆ı \%45,4 olarak saptanmıştır. ${ }^{[36]}$ Gaikwad ve ark., KBVDA olan Hint erkeklerinde CFTR varyantlarını değerlendirmişler ve sağlıklı grupta M470V polimorfizmini \%28 olarak bulmuşlardır. ${ }^{[37]}$ Her ne kadar toplumumuzdaki M470V polimorfizminin sıklığı hakkında veri olmasa da, yapılmış olan bu çalışmalara bakıldığında, sağlıklı popülasyona göre NOA ve şiddetli oligozoospermisi bulunan erkeklerde M470V sıklığının artmış olduğu ve araştırılması gereken etiyolojik bir faktör olabileceği söylenebilir. 


\section{SONUÇ}

$\mathrm{Bu}$ çalışmanın sonuçları, şiddetli oligozoospermi veya NOA’sı olan kişilerde gözlenen artmış M470V polimorfizminin, KBVDA dışında spermatogenez üzerine de etkileri olabileceğini düşündürmektedir. Ancak, bu konuyla ilgili daha kapsamlı çalışmalara ihtiyaç vardır.

\section{KAYNAKLAR}

1. Jungwirth A, Diemer T, Dohle GR, Giwercman A, Kopa Z , Krausz C, Tournaye H. Guidelines on Male Infertility. European Association of Urology 2015..

2. Greenhall E, Vessey M. The prevalence of subfertility: a review of the current confusion and a report of two new studies. Fertil Steril 1990;54:978-83.

3. Mosher WD, Pratt WF. Fecundity and infertility in the United States: incidence and trends. Fertil Steril 1991;56:192-3.

4. de Kretser DM. Male infertility. Lancet 1997;349:787-90.

5. Kerem B, Rommens JM, Buchanan JA, Markiewicz D, Cox TK, Chakravarti A, et al. Identification of the cystic fibrosis gene: genetic analysis. Science 1989;245:1073-80.

6. Riordan JR, Rommens JM, Kerem B, Alon N, Rozmahel R, Grzelczak Z, et al. Identification of the cystic fibrosis gene: cloning and characterization of complementary DNA. Science 1989;245:1066-73.

7. Holsclaw DS, Perlmutter AD, Jockin H, Shwachman H. Genital abnormalities in male patients with cystic fibrosis. J Urol 1971;106:568-74.

8. Chillon M, Casals T, Mercier B, Bassas L, Lissens W, Silber S, et al. Mutations in the cystic fibrosis gene in patients with congenital absence of the vas deferens. N Engl J Med 1995;332:1475-80. doi: 10.1056/NEJM199506013322204

9. de la Taille A, Rigot JM, Mahe P, Gervais R, Dumur V, Lemaitre $\mathrm{L}$, et al. Correlation of genitourinary abnormalities, spermiogram and CFTR genotype in patients with bilateral agenesis of the vas deferens. Prog Urol 1998;8:370-6.

10. Patrizio P, Salameh WA. Expression of the cystic fibrosis transmembrane conductance regulator (CFTR) mRNA in normal and pathological adult human epididymis. J Reprod Fertil Suppl 1998;53:261-70.

11. van der Ven K, Messer L, van der Ven H, Jeyendran RS, Ober C. Cystic fibrosis mutation screening in healthy men with reduced sperm quality. Hum Reprod 1996;11:513-7.

12. Cuppens H, Cassiman JJ. CFTR mutations and polymorphisms in male infertility. Int J Androl 2004;27:251-6. doi: 10.1111/j.13652605.2004.00485.x

13. Claustres M. Molecular pathology of the CFTR locus in male infertility. Reprod Biomed Online 2005;10:14-41.

14. Elborn JS. Cystic fibrosis. Lancet 2016;388:2519-31. doi: 10.1016/S0140-6736(16)00576-6

15. Yu J, Chen Z, Ni Y, Li Z. CFTR mutations in men with congenital bilateral absence of the vasdeferens (CBAVD): a systemic review and meta-analysis. Hum Reprod 2012;27:25-35. doi: 10.1093/ humrep/der377

16. de Meeus A, Guittard C, Desgeorges M, Carles S, Demaille J, Claustres M. Linkage disequilibrium between the M470V variant and the IVS8 polyT alleles of the CFTR gene in CBAVD. J Med Genet 1998;35:594-6.
17. Du Q, Li Z, Pan Y, Liu X, Pan B, Wu B. The CFTR M470V, intron 8 poly-T, and 8 TG-repeats detection in Chinese males with congenital bilateral absence of the vas deferens. Biomed Res Int 2014;2014:689185. doi: 10.1155/2014/689185

18. Neto FT, Bach PV, Najari BB, Li PS, Goldstein M. Genetics of male infertility. Curr Urol Rep 2016;17:70. doi: 10.1007/s11934016-0627-x

19. Krausz C. Male infertility: pathogenesis and clinical diagnosis. Best Pract Res Clin Endocrinol Metab 2011;25:271-85. doi: 10.1016/j.beem.2010.08.006

20. Kosova G, Scott NM, Niederberger C, Prins GS, Ober C. Genome-wide association study identifies candidate genes for male fertility traits in humans. Am J Hum Genet 2012;90:950-61. doi: 10.1016/j.ajhg.2012.04.016

21. Horsthemke B, Ludwig M. Assisted reproduction: the epigenetic perspective. Hum Reprod Update 2005;11:473-82. doi: 10.1093/ humupd/dmi022

22. Oliva R. Protamines and male infertility. Hum Reprod Update 2006;12:417-35. doi: 10.1093/humupd/dml009

23. Baldinotti F, Majore S, Fogli A, Marrocco G, Ghirri P, Vuerich $\mathrm{M}$, et al. Molecular characterization of 6 unrelated Italian patients with 5alpha-reductase type 2 deficiency. J Androl 2008;29:20-8. doi: 10.2164/jandrol.107.002592

24. Foresta C, Ferlin A, Gianaroli L, Dallapiccola B. Guidelines for the appropriate use of genetic tests in infertile couples. Eur J Hum Genet 2002;10:303-12. doi: 10.1038/sj.ejhg.5200805

25. Galani A, Kitsiou-Tzeli S, Sofokleous C, Kanavakis E, KalpiniMavrou A. Androgen insensitivity syndrome: clinical features and molecular defects. Hormones (Athens) 2008;7:217-29.

26. Safinejad K, Darbouy M, Kalantar SM, Zeinali S, Mirfakhraie R, Yadegar L, et al. The prevalence of common CFTR mutations in Iranian infertile men with non-CAVD obstructive azoospermia by using ARMS PCR techniques. J Assist Reprod Genet 2011;28:1087-90. doi: 10.1007/s10815-011-9632-7

27. Ghorbel M, Baklouti-Gargouri S, Keskes R, Sellami-Ben Hamida A, Feki-Chakroun N, Bahloul A, et al. Screening of $\triangle$ F508 mutation and IVS8-poly $\mathrm{T}$ polymorphism in CFTR gene in Tunisian infertile men without CBAVD. Andrologia 2012;44 Suppl 1:376-82. doi: 10.1111/j.1439-0272.2011.01193.x

28. Lu S, Yang X, Cui Y, Li X, Zhang H, Liu J, et al. Different cystic fibrosis transmembrane conductance regulator mutations in Chinese men with congenital bilateral absence of vas deferens and other acquired obstructive azoospermia. Urology 2013;82:824-8. doi: 10.1016/j.urology.2013.06.024

29. Ferlin A, Arredi B, Foresta C. Genetic causes of male infertility. Reprod Toxicol 2006;22:133-41. doi: 10.1016/j. reprotox.2006.04.016

30. Schulz S, Jakubiczka S, Kropf S, Nickel I, Muschke P, Kleinstein J. Increased frequency of cystic fibrosis transmembrane conductance regulator gene mutations in infertile males. Fertil Steril 2006;85:135-8. doi: 10.1016/j.fertnstert.2005.07.1282

31. Sharma H, Mavuduru RS, Singh SK, Prasad R. Increased frequency of CFTR gene mutations identified in Indian infertile men with non-CBAVD obstructive azoospermia and spermatogenic failure. Gene 2014;548:43-7. doi: 10.1016/j.gene.2014.07.005

32.Schwarzer JU, Schwarz M. Significance of CFTR gene mutations in patients with congenital aplasia of vas deferens with special regard to renal aplasia. Andrologia 2012;44:305-7. doi: 10.1111/j.14390272.2012.01281.x

33. Chen H, Ruan YC, Xu WM, Chen J, Chan HC. Regulation of male fertility by CFTR and implications in male infertility. Hum Reprod Update 2012;18:703-13. doi: 10.1093/humupd/dms027 
34. Nefzi M, Hadj Fredj S, Tebib N, Barsaoui S, Boussetta K, Siala $\mathrm{H}$, et al. Contribution of M470V variant to cystic fibrosis: First study in CF and normal Tunisian population. Pathol Biol (Paris) 2015;63:169-74. doi: 10.1016/j.patbio.2015.07.004

35. Stankovic M, Nikolic A, Divac A, Tomovic A, Petrovic-Stanojevic $\mathrm{N}$, Andjelic M, et al. The CFTR M470V gene variant as a potential modifier of COPD severity: study of Serbian population. Genet Test 2008;12:357-62. doi: 10.1089/gte.2007.0069
36. Huang Q, Ding W, Wei MX. Comparative analysis of common CFTR polymorphisms poly-T, TG-repeats and M470V in a healthy Chinese population. World J Gastroenterol 2008;14:1925-30.

37. Gaikwad A, Khan S, Kadam S, Kadam K, Dighe V, Shah R, et al. The CFTR gene mild variants poly-T, TG repeats and M470V detection in Indian men with congenital bilateral absence of vas deferens. Andrologia 2017. doi: 10.1111/and.12858 